\title{
Numerical Analysis of HyShot Scramjet Model with Different Throat Heights
}

\author{
Fei Xing ${ }^{1}$ \\ School of Aerospace Engineering, Xiamen University, Xiamen 361005, China \\ -IDQ TIDQ\& ${ }^{2}$ \\ School of Aerospace Engineering, Xiamen University, Xiamen 361005, China \\ Yue Huang ${ }^{3}$ \\ School of Aerospace Engineering, Xiamen University, Xiamen 361005, China \\ and \\ Yufeng $\mathrm{Yao}^{4}$ \\ Department of Engineering Design and Mathematics, University of the West of England, BristolBS16 1QY, UK
}

\begin{abstract}
This paper presents a computational fluid dynamics (CFD) study of non-reacting and reacting flows in a scramjet model with three different throat heights. This scramjet model includes two compression ramps at the inlet, followed by a combustion chamber and thrust surfaces. The hydrogen is injected through an array of holes on the ramp surfaces, and the ignition is trigged by increased gas mixture temperature due to strong shock-shock interactions. The primary goal of the study is to evaluate the detailed shock-inducedcombustion processes by comparing CFD predictions with available experimental data, thus to understand the underlying combustion flow physics. For the 'fuel off' cases, it was found that the CFD simulation produces the wall pressures in good agreement with the measurements. While for the 'fuel on' cases, the CFD simulation results of combustion flow exhibit strong dependence on the turbulence model and turbulent combustion model choices. The desirable 'radical farming' process has been only partially achieved in the flow field adjacent to the combustor walls, mainly due to the lacking of the penetration depth from the injector to the center main flow. The effect of fuel injection angle could affect the penetration depth and also the specific thrust of the scramjet engine.
\end{abstract}

\section{Nomenclature}

$M_{\infty} \quad=$ Mach number of scramjet inlet air

$\mathrm{N}_{\mathrm{x}} \quad=$ grid points in streamwise direction

$\mathrm{N}_{\mathrm{y}} \quad=$ grid points in wall normal direction

$P_{\infty} \quad=$ pressure of scramjet inlet air

Re $\quad=$ Reynolds number

$T_{\infty} \quad=$ temperature of scramjet inlet air

$\rho_{\infty} \quad=$ density of scramjet inlet air

$u_{\infty} \quad=$ velocity of scramjet inlet air

$\mathrm{y}^{+} \quad=\mathrm{y}$-coordinate in wall unit

$\Delta \mathrm{y}_{1} \quad=$ mesh size of the first grid in near wall

$\varphi \quad=$ equivalence ratio

\footnotetext{
${ }^{1}$ Associate Professor, School of Aerospace Engineering, Xiamen University, Xiamen, Fujian 361005, China, f.xing@xmu.edu.cn

${ }^{\frac{1}{2}}$ Graduate student, School of Aerospace Engineering, Xiamen University, Xiamen, Fujian 361005, China

${ }^{3}$ Associate Professor, School of Aerospace Engineering, Xiamen University, Xiamen, Fujian 361005, China, huangyue@xmu.edu.cn

${ }^{4}$ Professor, Department of Engineering Design and Mathematics, University of the West of England, Frenchay Coldharbour Lane, Bristol BS16 1QY, United Kingdom, Associate Fellow AIAA.Yufeng.Yao@uwe.ac.uk
} 


\section{Introduction}

$\mathrm{H}$ igh-speed flight in the Earth's atmosphere has many applications for transport, defense, and space access. In order to avoid carrying a large amount of on-board oxidizer, one recent trend of hypersonic flight vehicle design was the development and application of supersonic combustion ramjet (scramjet), a variant of ramjet air breathing jet engine, in which combustion takes place at supersonic airflow speed ${ }^{1}$. There are several advantages of applying this engine type; e.g. flow remaining in supersonic speed thus having lower static temperature and pressure even after the diffuser, reduction of dissociation problems as the gases being expanded in the engine exhaust, and reduced diffuser losses, etc. However, high velocity flow inside the scramjet combustion chamber often poses some great challenges for the air/fuel mixing and combustion progress within desirable length scales, due to the coexistence of complex shock-shock, shock/boundary-layer and shock-flame interactions.

One feasible technology is to inject the fuel from locations after the leading-edge shock-wave and before (but close to) the engine inlet, thus using the leading-edge shock-wave to provide an environment conducive for the air and fuel mixing, compressing and heating production. Whilst the air/fuel gas mixture enters into the combustor chamber, it will then automatically ignite and the chemical reaction could proceed under conditions of the appropriate static pressure and temperature, in corresponding to the flow Mach number. As this technology does not need any ad hoc ignition system, it can reduce the surface area and thus minimize the size of a combustion chamber.

Scramjet researches by earlier investigators generally took a method of injecting fuel in the region where combustion occurred ${ }^{2}$. Different to low-speed combustion, supersonic flow combustion highly depends on compressed air temperatures, shock strengths, hot pilots, and quite often a combination of these factors in order to produce an auto-ignition. While the quality of air/fuel mixing can be obtained by carefully tuned combination of turbulence level, shock patterns and diffusions, the interactions between aerodynamic flow and chemical reaction and the consequent instability issues will generate more complex problems in designing a propulsion system with better performance. Some extensive works have been done in the past to resolve these 'known' problems ${ }^{3}$. In common, it follows a rule of thumb of thermochemical kinetics of the reacting flows ${ }^{4}$, i.e. using shock-wave to produce high compression that can raise the static air temperature to higher value above the ignition temperature of the fuel. When this occurs, the combustion of an air and fuel gas mixture will begin automatically without having an igniter.

An example study of shock-induced-combustion with inlet fuel injection has been focused on Mach 6.5 using a ground test facility at University of Queensland, Australia and one unique phenomenon known as "radical farming" was observed and discussed based on the experimental measurements. Gardner et al. ${ }^{5}$ demonstrated the ability to inject gaseous hydrogen fuel at the inlet that could achieve auto-ignition and combustion inside the combustion chamber without an igniter. Mudford et al. ${ }^{6}$ reported two-dimensional (2-D) computational results that were compared with surface pressure measurements for cases with and without fuel injection into a free stream flow of nitrogen and/or air. Their comparisons showed that the computation produced physically sound results and predicted many key flow features quite accurately, but unfortunately failed to capture the significant combustion feature in this type of air/fuel mixing flow; i.e. "radical farming". This concept was further studied by Odam ${ }^{7}$ and Odam and Paull $^{8}$, who used a 2-D scramjet model with an adjustable throat height to determine the minimum contraction ratio that would facilitate combustion of gaseous hydrogen at relatively lower mean static pressure and temperature than generally required. A simplified theoretical analysis of the "radical farming" concept was also derived and presented. Positive net specific impulse estimations were obtained at certain minimum equivalence ratio, which was dependent on the contraction ratio of the throat and as well as the test conditions. These studies also indicated that the combination of inlet fuel injection and the "radical farming" phenomenon would enable a combustion occurred at relatively low inlet contraction ratio without the use of physical flame holders.

Following these pioneering work, other researchers began to study this interesting concept in further breadth and depth. For example, simulation study of an ethylene-fueled three-dimensional (3-D) scramjet model by Brindle et al. ${ }^{9}$ showed that due to the Jachimowski reaction mechanism ${ }^{10}$, the 3-D calculation resulted in extremely limited combustion. An increase of the scramjet scale by one order of magnitude would enhance the extent of combustion, but still not sufficiently large to produce any significant pressure and temperature rise at the entrance of combustion chamber. Star et al. ${ }^{11}$ presented 3-D CFD simulations of steady-state reactive flow using a hydrogen-fueled scramjetlike geometry model. While their computational results did provide some hard evidences in supporting the "radical farming" hypothesis, it was appeared to experience some remarkable sensitivities to the wall temperature boundary conditions, indicating that there is the critical need to account for the transient wall heating in simulations. Jones ${ }^{12}$ performed a 2-D intake fuel injection simulation using different turbulence models. The results showed that the combustion performance was very sensitive to the number of grid cells used in the wall normal direction. Another simulation study by Chan et al. ${ }^{13}$ showed that the intake fuel injection could make the scramjet engine appreciably 
smaller and lighter, thus requiring much less cooling even for a Mach 11 flight. A numerical study of a 2-D model by Buttsworth and Jacobs ${ }^{14}$ offered an alternative approach by using inlet-injection method for the investigation and identification of premature ignition regimes which should be avoided in scramjet engine designs.

A recent investigation of inlet fuel injection in a scramjet model with a three-dimensional inlet configuration and an elliptical combustion chamber was undertaken by Turner and Smart ${ }^{15}$. Experiments were conducted using a test flow facility representing a Mach 8.1 flight condition at an altitude of $32 \mathrm{~km}$. Results indicated that inlet injection produced robust supersonic combustion at high efficiency over a large fueling range up to an equivalence ratio of 0.92. In addition, no evidence of combustion was observed in the inlet region.

In the present study, three symmetrical Hyshot scramjet model configurations, experimentally studied by Odam et al. ${ }^{7,8}$, will be re-visited by a computational fluid dynamics (CFD) solution based on solving Reynolds-averaged Navier-Stokes equations with turbulence and combustion models. Both grid sensitivity and turbulent model assessment will be carried out and the comparisons of surface pressure distributions with the experimental data will be made. In particular, three different throat height cases will be analyzed in a systematic manner and CFD predicted static pressure, temperature, fuel concentration and heat release will be compared with the available experimental data. The primary goal of the present research is to investigate how the combustor throat height variations would affect the progress of the shock-induced combustion, thus to assess the feasibility of inlet fuel injection method for high-speed scramjet applications.

\section{Model and Simulation Description}

\section{A. Model Configuration}

Figure 1 gives a sketch of a cross-section of a full scale laboratory scramjet test model. The model has two vertical sidewalls and horizontal upper and lower walls in a symmetric arrangement against the horizontal middle plane. It has a longitudinal length of $625 \mathrm{~mm}$ and a spanwise width of $75 \mathrm{~mm}$ at the inlet and the outlet planes of a rectangular duct shape, respectively. The intake section is $180 \mathrm{~mm}$ long, and the height of the inlet varies from $82 \mathrm{~mm}$ for a throat height of $20 \mathrm{~mm}$ up to $94 \mathrm{~mm}$ for a throat height of $32 \mathrm{~mm}$, and the first ramp is formed by a sharp nosed flat plate at a deflection angle of $9^{\circ}$. At $135 \mathrm{~mm}$ downstream from the leading edge, the second ramp is applied with a deflection angle of $12^{\circ}$ against horizontal plane to form a compression corner.

After the intake section, there is $250 \mathrm{~mm}$ long combustion chamber section at a constant height throughout with three different scenarios; namely Case 20 at a throat height of $20 \mathrm{~mm}$, Case 24 at a throat height of $24 \mathrm{~mm}$, and Case 32 at a throat height of $32 \mathrm{~mm}$, respectively. The diffuser portion has a fixed length of $195 \mathrm{~mm}$ for all three scenarios. The hydrogen fuel is injected from four injection ports that are located on both upper and lower intake ramps at an axial distance of $95 \mathrm{~mm}$ from the leading edge, denoted with two black dots in Figure 1. The ports have same crosssection diameter of $2 \mathrm{~mm}$ and an inclined angle of $45^{\circ}$ against the ramp surface, leading to $54^{\circ}$ against the horizontal plane. The red and green dashed lines illustrate the inviscid shock-waves from the inlet and the compression corner and their reflections, and the expansion-waves from the entrance of combustion section and their reflections along the combustor surfaces, respectively. The yellow diamond pattern enclosed by the shock and expansion wave lines denotes where the so-called "radical farming" combustion would occur.

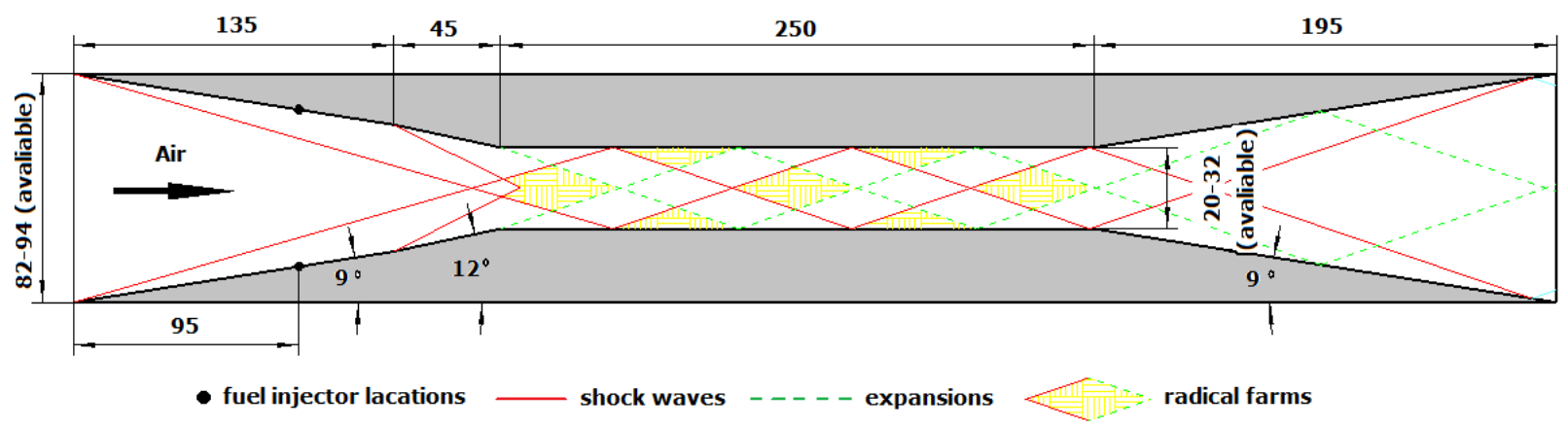

Figure 1. Schematic description of the experimental scale scramjet model [7]. 


\section{B. Computational Setup}

In the present study, results from three-dimensional steady CFD simulations are going to compare with experimental data from Mudford et al. ${ }^{6}$ and Odam ${ }^{7}$ for both "fuel off" (non-combustion) and "fuel on" (combustion) cases.

A commercial CFD software ANSYS-CFX ${ }^{16}$ is applied, that contains various sub-models to simulate turbulent combustion phenomena. Several key elements will be explored to assess the capabilities of the software in simulating shock-wave/boundary-layer and shock-shock interactions, mass, momentum and heat transfer transport characteristics between injected fuel and mainstream supersonic air flow, and turbulent combustion.

For "fuel off" case, the absence of fuel jets means that the 3-D effects are presented only in corner regions, due the existence of the sidewalls and associated boundary layers. Therefore, by following common practices, 2-D simulation of a mid-plane slice was chosen that permits high efficient computations for a wide range of parametric studies, such as flow conditions, grid refinement, turbulence models, and results could be comparable with those from 3-D model measurements on the centerline plane. After the grid sensitivity and turbulence models choice assessment, a3-D mesh is constructed by considering the sidewall effect and it can be used for both "fuel off" and "fuel on" cases. Note that due to less spanwise flow movement in comparison to that of streamwise and wall normal directions, only a quarter of the scramjet model is meshed with two injection ports located on both lower and upper walls. Figure 2 shows the computational mesh used in the calculations. The multi-block structured mesh was generated by using commercial software ICEM.

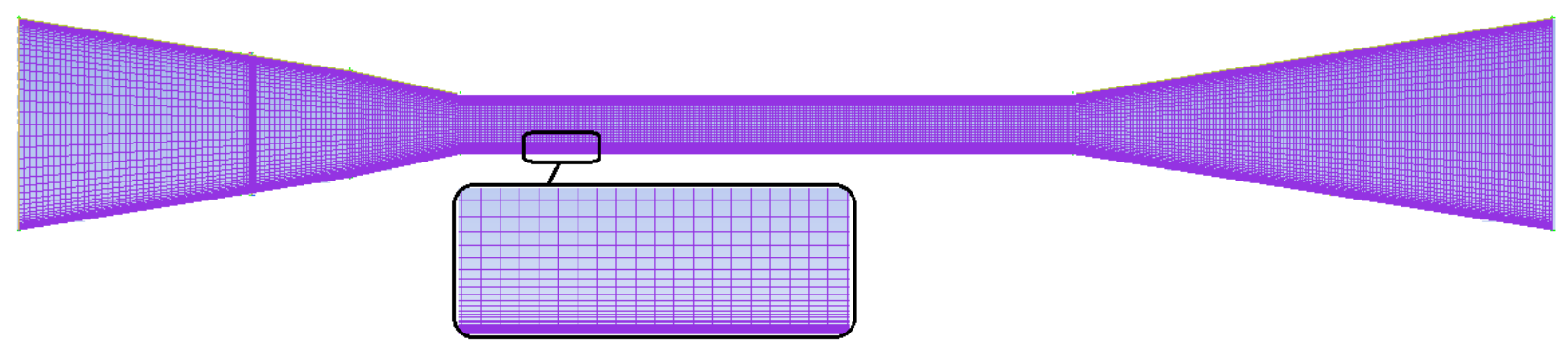

Figure 2. Sample multi-block structured mesh with close views at throat area.

\section{Grid and Model Sensitivity}

\section{A. Grid Sensitivity}

The flow conditions for 2-D simulation of grid sensitivity and turbulence models are incoming Mach number (M $\infty)$ of 6.5 , static pressure $\left(\mathrm{P}_{\infty}\right)$ of $10.5 \mathrm{KPa}$, static temperature $\left(\mathrm{T}_{\infty}\right)$ of $310 \mathrm{~K}$, and Reynolds number $(\mathrm{Re})$ of $7 \times 10^{6}$, based on the characteristic length of $625 \mathrm{~mm}$ and the free stream quantities. These parameters are taken from the experimentalmeasurements ${ }^{6}$.

The boundary conditions are uniform supersonic inflow at the inlet plane, and supersonic outflow conditions at the outlet plane. The top and bottom surfaces use no-slip adiabatic wall condition. For steady state simulation, convection terms are discretised with a second-order scheme ${ }^{17}$, and the simulation is initialized by using the inlet flow conditions.

Due to higher deflection angle of $12^{\circ}$ of the second ramp, Menter's shear stress transport (SST) turbulence model $^{18}$, which is more suitable for separated flow modeling, is used in the grid sensitivity studies. For Case 24 with a throat height of $24 \mathrm{~mm}$, a total of 12 grids were generated with different numbers of grid points along the streamwise $\left(N_{x}\right)$ and the wall-normal $\left(N_{y}\right)$ directions, as shown in Reference 19. Therefore, based on incoming flow conditions and mesh size of the first grid next to the wall surface, different $\mathrm{y}^{+}$value can be estimated to ensure the validity of applying SST model. In addition, the development of wall boundary layer in terms of its viscous thickness is carefully estimated and used to resolve the wall boundary layers and the shock reflections at the wall.

Also the simulation cases with less wall-normal-direction grids did not accurately capture the reflection of the shock-wave after interacting with the boundary layer. Further refinement in the wall-normal direction is required, e.g. by doubling grid points in the wall-normal direction. While the wall resolution in terms of $\mathrm{y}^{+}$reduces, simulation results have showed some improvements in comparison with the experimental data. The CFD predictions are quite promising in terms of the locations of all four peaks, but clearly under-predicts the magnitude of peak values. 


\section{B. Turbulence and Combustion Model Sensitivity}

Some popular two-equation turbulence models such as $k$ - $\varepsilon$ model and Shear-Stress-Transport (SST) model are considered for assessing their capability for cases with strong shock-wave/boundary-layer interactions that may cause flow separation and also shock-induced-combustion phenomenon. The RANS CFD with $k$ - $\varepsilon$ model is nowadays considered as an industry standard approach. The method has been proven to be stable and numerically robust and has a well-established regime of predictive capability. For industry applications, the $k-\varepsilon$ model offers a good compromise in terms of accuracy and robustness. Within ANSYS-CFX, the $k$ - $\varepsilon$ turbulence model uses the scalable wall-function approach to further improve robustness and accuracy when the near-wall mesh is very fine. The SST model, initially proposed by Menter ${ }^{20}$ and further validated by Bardina et al. ${ }^{21}$ among many others, is a variant of the $k-\omega$ model. It was designed to give more accurate predictions of the onset and the extent of flow separation under adverse pressure gradient conditions by the inclusion of transport effects into the eddy-viscosity formulation. This will result in a major improvement in terms of flow separation predictions. The Reynolds stresses model has six additional transport equations that are solved at each time-step or for the outer iteration loop in the flow solver. The source terms in the Reynolds Stress equations are also more complicated than those of the $k-\varepsilon$ model. So, it would be more suitable for the flows where the turbulent transport and/or non-equilibrium effects are important, such as supersonic combustion flows in this study.

Reference 19 gives simulation results using six turbulence models; i.e. standard $k-\varepsilon$, renormalized group $k-\varepsilon$ (denoted as RNG $k-\varepsilon$ thereafter), eddy-viscosity transport (EVT), baseline Reynolds stress model (BSL RS), standard $k-\omega$, and SST models, respectively. Based on the comparison between the predicted centerline wall pressure distributions in with the measurement data, $\mathrm{k}-\varepsilon$, RNG k- $\varepsilon$ and EVT turbulence model can calculate the accurate pressure distribution.

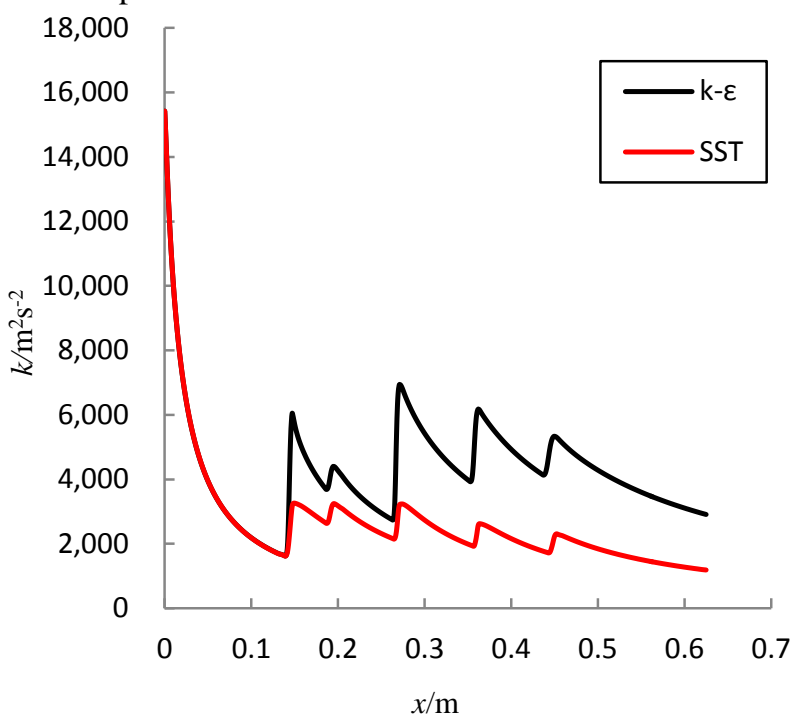

(a) turbulence energy $k$

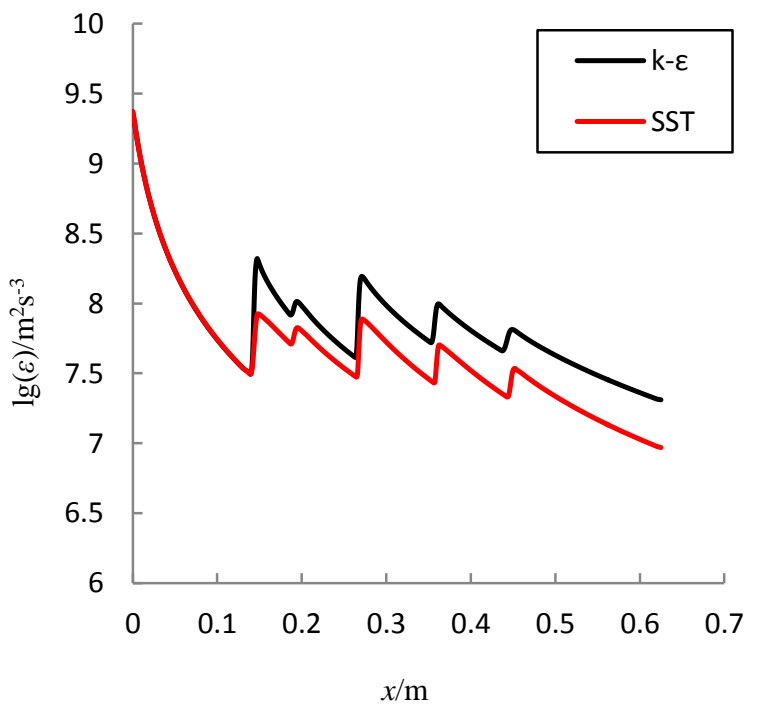

(b) turbulent dissipation rate $\log (\varepsilon)$

Figure 3. Cold flow centerline turbulence parameter profile with $k-\varepsilon$ and SST turbulence models [22].

The wall pressure distribution in the cold flow is mainly determined by the shock wave, and the influence of the turbulence is relatedly small, so the different turbulence models are used to calculate the turbulence parameters with no obvious differences.

However, the centerline turbulence parameters obtained from the comparison with $k-\varepsilon$ and SST Turbulence model differ a lot, as shown in Figure 3 from [22]. Due to shock-wave/boundary-layer interactions, turbulent motions will be much enhanced and sometimes even be elevated. Hence when the airflows travel through a shockwave line, it is expected to observe a clear step change in turbulence kinetic energy and dissipation rate as showed in Figure 3, and two parameters are gradually dissipated until interacting with the next shock-wave. It can be seen from Figure 3 that while the locations of observed jumps are the same, the magnitudes are quite different and they are dependent on the turbulence model used; e.g. the $k$ - $\varepsilon$ model exhibits large jump compared to that of the SST model. References [23-24] demonstrated that in general the SST model is more suitable to calculate the turbulence properties, associated with shock-wave/boundary-layer interactions, with higher accuracy, so it can be reasonably 
concluded that the $k-\varepsilon$ model may over-predicted the turbulence level after interacting with shock-wave, and this will be further confirmed by combustion calculation results shown in Figure 4.

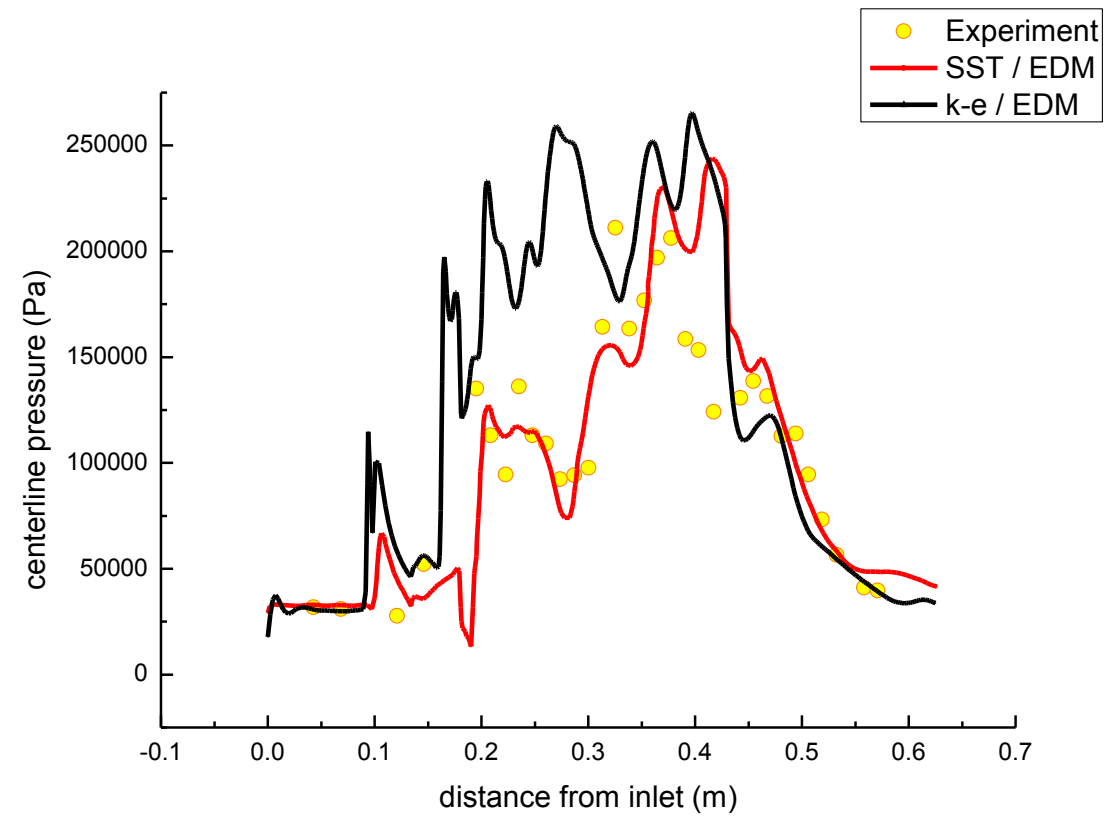

Figure 4. Comparisons of the lower wall centerline pressure distributions with different models [25].

From figure 4, it can be seen that SST calculated results are in better agreement with the experimental data, while the $k-\varepsilon$ turbulence model largely over-predicts the centerline pressure for the internal flowfield of the combustor rom over a wide range of ' $A$ ' value used in combustion eddy-dissipation model (EDM), to be discussed latter. The obvious advantage of using the SST model is that it can accurately simulate two turbulent flow mechanisms (its generation with increased kinetic energy and subsequent dissipation), so the SST model is most likely able to calculate the fuel/air turbulent mixing process more accurately. Several 'A' values in EDM turbulent combustion model were tested, and the results are broadly in good agreement with the experimental data, with the constant $A=2$ produces the best predictions (from [22]). In contrary, the k- $\varepsilon$ model predicts unrealistic and far too quick fuel and air mixing, and thus the chemical reaction begins at a location not far from the fuel injector exit, due to relatively faster reaction rate. At the same time, the fuel and air are fully mixed fairly quickly, with significantly high peak pressure, which cause the calculation results and experimental data are not in agreement even qualitatively.

\section{Simulation Results and Discussion}

Both non-reacting "fuel off" and reacting "fuel on" flow cases will be investigated here. The experimental data were from two studies previously being carried out in T4 shock tunnel facility at University of Queensland ${ }^{6,7}$, and the experimental conditions are summarized in Table 1. For 3-D simulations, the number of grid points in the spanwise $z$-dir $\left(N_{z}\right)$ is 30 and the values of $\mathrm{y}+$ is around $0.5-2$.

Table 1. Scramjet simulation conditions [6-7]

\begin{tabular}{|l|c|c|c|c|c|c|}
\hline & Case20 & Case24 & Case32 & Case20 & Case24 & Case32 \\
\hline$\varphi$ & 0 & 0 & 0 & 0.36 & 0.39 & 0.4 \\
\hline $\mathrm{M}_{\infty}$ & 6.78 & 6.5 & 6.74 & 6.40 & 6.5 & 6.51 \\
\hline $\mathrm{P}_{\infty}(\mathrm{Pa})$ & 7253 & 10500 & 8063 & 9131 & 10500 & 8030 \\
\hline $\mathrm{T}_{\infty}(\mathrm{K})$ & 280 & 310 & 285 & 422 & 310 & 375 \\
\hline$\rho_{\infty}\left(\mathrm{kg} / \mathrm{m}^{3}\right)$ & 0.0902 & 0.116 & 0.0987 & 0.0755 & 0.116 & 0.0746 \\
\hline $\mathrm{u}_{\infty}(\mathrm{m} / \mathrm{s})$ & 2275 & 2296 & 2279 & 2634 & 2296 & 2527 \\
\hline
\end{tabular}


The symbols $\varphi, \mathrm{M}_{\infty}, \mathrm{P}_{\infty}, \mathrm{T}_{\infty}, \rho_{\infty}$ and $\mathrm{u}_{\infty}$ stand for equivalence ratio, inlet Mach number, inlet static pressure, inlet static temperature, inlet density and inlet velocity, respectively. The initial and inflow boundary conditions for simulations are determined by using the exactly parameters seen in Table 2.In case of "fuel on" simulations, the fuel jet velocity, density and temperature are $1206 \mathrm{~m} / \mathrm{s}, 0.543 \mathrm{~kg} / \mathrm{m}^{3}$ and $250 \mathrm{~K}$, respectively.

\section{A. 'Fuel off' Simulation}

Figure 5 gives CFD predicted pressure distributions along the centerline of the lower wall surface in comparison with experimental data for three different throat heights with "fuel off" conditions. It can be seen that three-stage compressions occur as the air flow passes through the shock-waves forming from the first and the second compression wedges, and subsequent shock trains inside the combustion chamber channel. In spite of the complexities of the shock-wave/boundary-layer interactions, the predicted wall pressure distributions inside the combustion chamber are in good agreement with test data for Case 24 and Case 32, including the peak pressure on the thrust faces, at a slightly forward off-set location. For Case 20 of narrow throat, the first and the third peaks in the combustor were predicted lower than that of the experimental measurement.
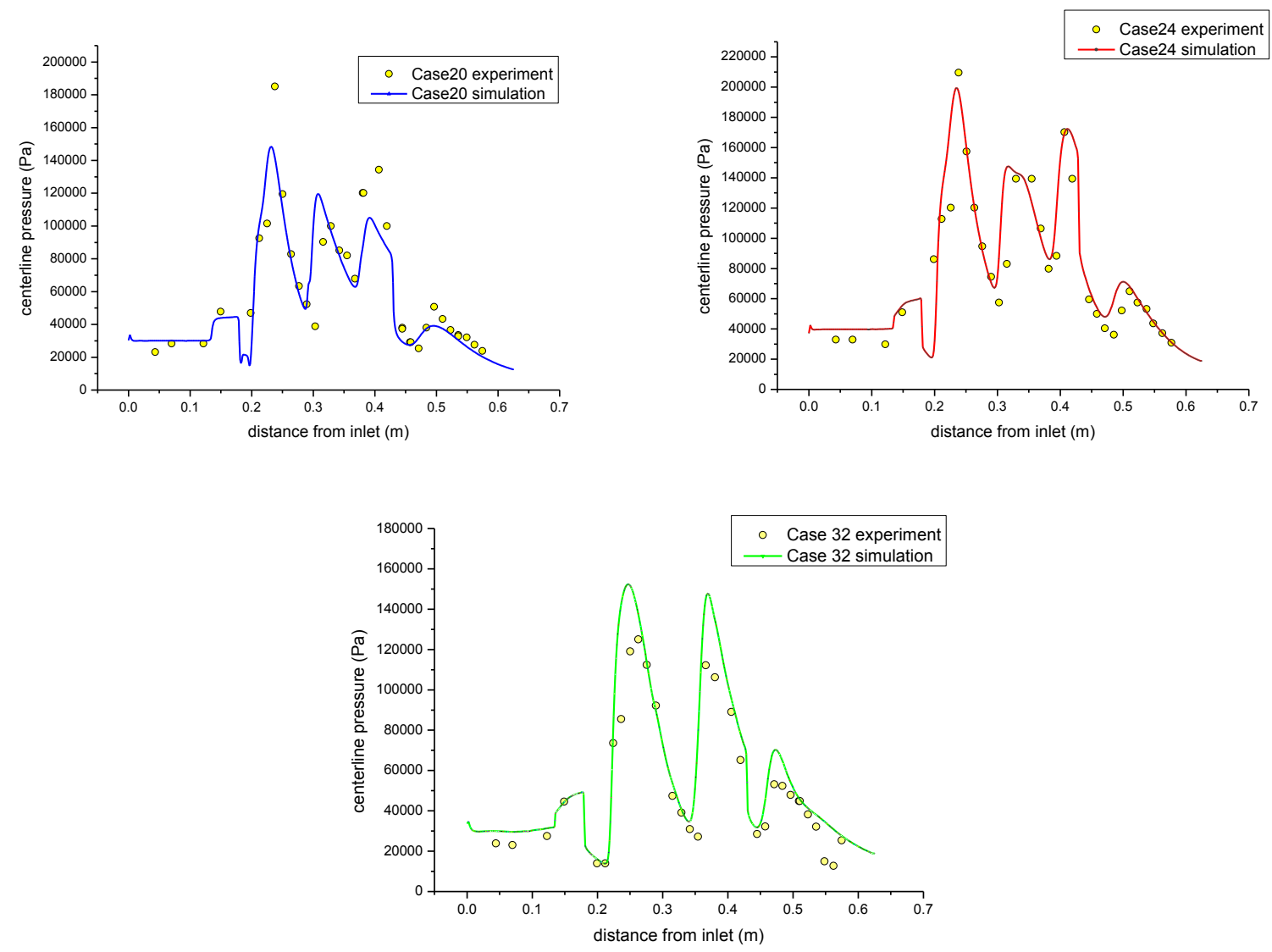

Figure 5. Comparisons of the lower wall centerline pressure distributions for three different cases.

Figure 6 shows contours of simulation pressures at a mid-plane for three different throat height cases at "fuel off" conditions. It can be seen that in all three cases, shock waves are forming from the $9^{\circ}$ intake ramps and they interact at a downstream location at centerline and are refracted through each other. The shocks passing through into the opposite combustion chamber walls without impinging onto the intake ramp wall surfaces satisfy the scramjet designrequirement ${ }^{7}$. Later these refracted shocks will encounter and interact with shock-waves formed from the second intake ramp angle of $12^{\circ}$ at first and then subsequently with the expansion waves formed from two corners (shoulders) of the opposite walls. All these will be further reflected when they reach the opposite walls. The refractions continue and produce a shock train of alternating shock waves and expansion waves all the way down to the diffuser duct at gradually weakened strengths. 
Figures 5 and 6 also show that the number of pressure peaks and their positions are different for three cases of varying throat heights. As the combustion chamber throat height increases, the location of the shock-wave and expansion-wave and their reflections changes significantly and this will have significant effects on the wall pressures measured along the surface. In fact, there are only two shock-wave reflections occurring within the length of the combustion chamber for Case 32 in which the shock strikes towards the end of the thrust surface, resulting in a very low pressure of between 10 and $20 \mathrm{kPa}$ on the thrust surface.

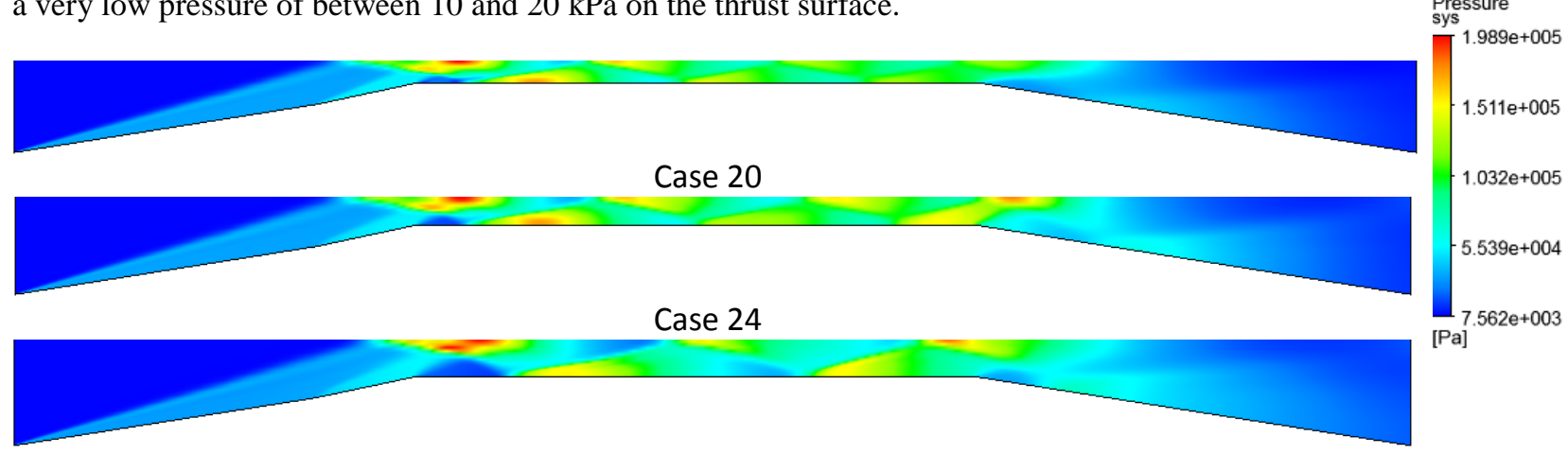

Case 32

Figure 6. Mid-plane pressure contours for three different cases.

The interaction of impinging and reflecting shock waves and expansion waves from the combustor wall surfaces will form a diamond shape, and furthermore the symmetry of the combustor allows for the creation of half a diamond shape adjacent to the combustor upper and lower surfaces (see Figure 1). These full and half a diamond shapes are the zones with higher pressure and temperature, which are ideal conditions for auto-ignition to be occurred. Combustion will happen within these diamond shape regions inside the combustor via a process known as "radical farming". The double compression processes after the engine inlet is still not sufficient for a complete combustion to occur in a single discrete diamond region, therefore it is intended as the flow passes by the expansion waves at the trailing edge of the diamond shape, where the pressure and temperature differential will be sufficient high to halt the reaction process ${ }^{6}$.

Figure 7 gives temperature contours. It can be seen that as the flow reaches the diamond regions where temperature and pressure increase above critical auto-ignition values, the combustion process would be reactivated automatically. But it should be noticed that the high temperature zones are not only found inside the diamond region, but also inside the boundary-layer near the upper and lower walls. The temperature in these zones will exceed $1500 \mathrm{~K}$, hence combustion will also occur in those near wall regions. It can be seen in Figure 7 that the increase of throat heights will result in larger near wall diamond zones with higher temperature. Also there is high temperature in region around half a diamond zone; hence the reaction will occur in these regions as well.

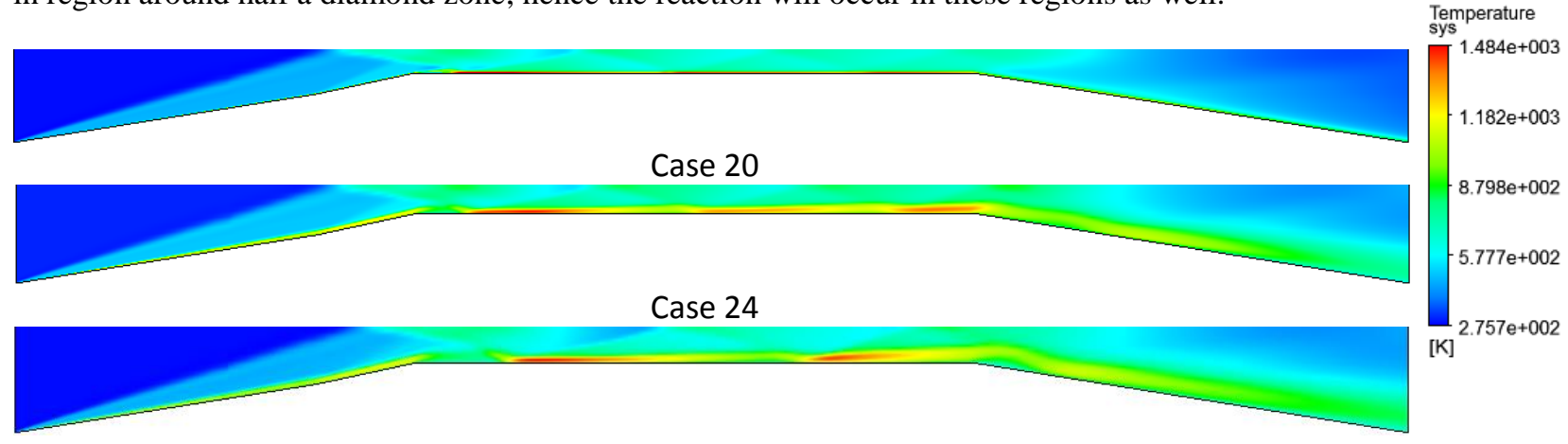

Case 32

Figure 7. Mid-plane temperature contours for three different cases.

\section{B. 'Fuel on' Simulation}

The "radical farming" phenomenon provides a means by which the combustion can happen even with mild intake compressions, which could lead to greater intake efficiency (due to less total pressure loss) and overall higher scramjet engine performance. The temperature and pressure differentials occurring in the expansion fans at the 
trailing edge of the diamond shapes will govern the rate at which the global hydrogen oxidation reaction occurs in these regions.

In order to have further physical insight to the extent of fuel and air mixing without combustion, the 'frozen' flow simulations have been carried out, in which all reaction rates set to zero chemically frozen flow, thus it replicates the fuel injection into the experimental flow. By comparison of the wall pressure contours of two adjacent walls of three-dimensional geometry as shown in Figure 8, it clearly demonstrates the effect of gas property changes on the shock structures. The most obvious change is the shock structure due to the first compression wedge where it impinges onto the upper combustor surface. This type of contour variations between "fuel off" and "fuel on" flow conditions is apparent at all locations where the shock impinges on the combustor surface in the mixing flow, indicating that the fuel has changed the properties adjacent to the combustor walls.

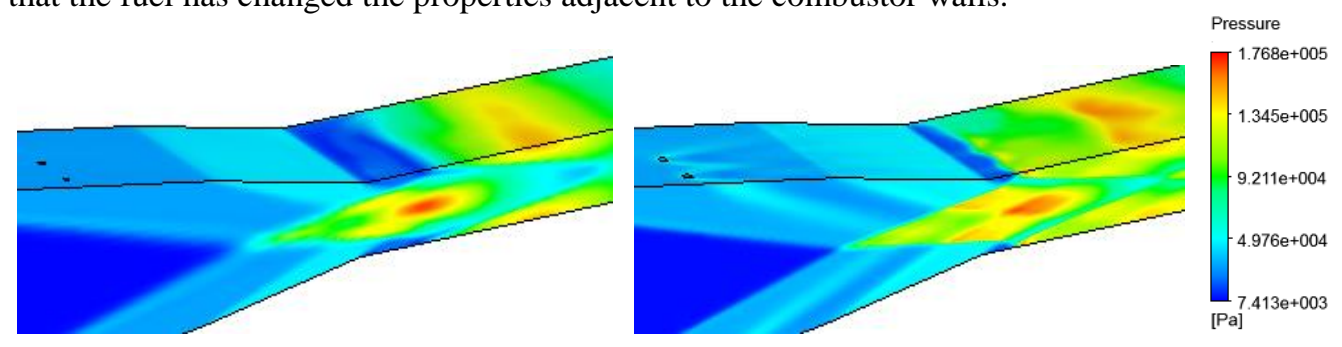

Case 20
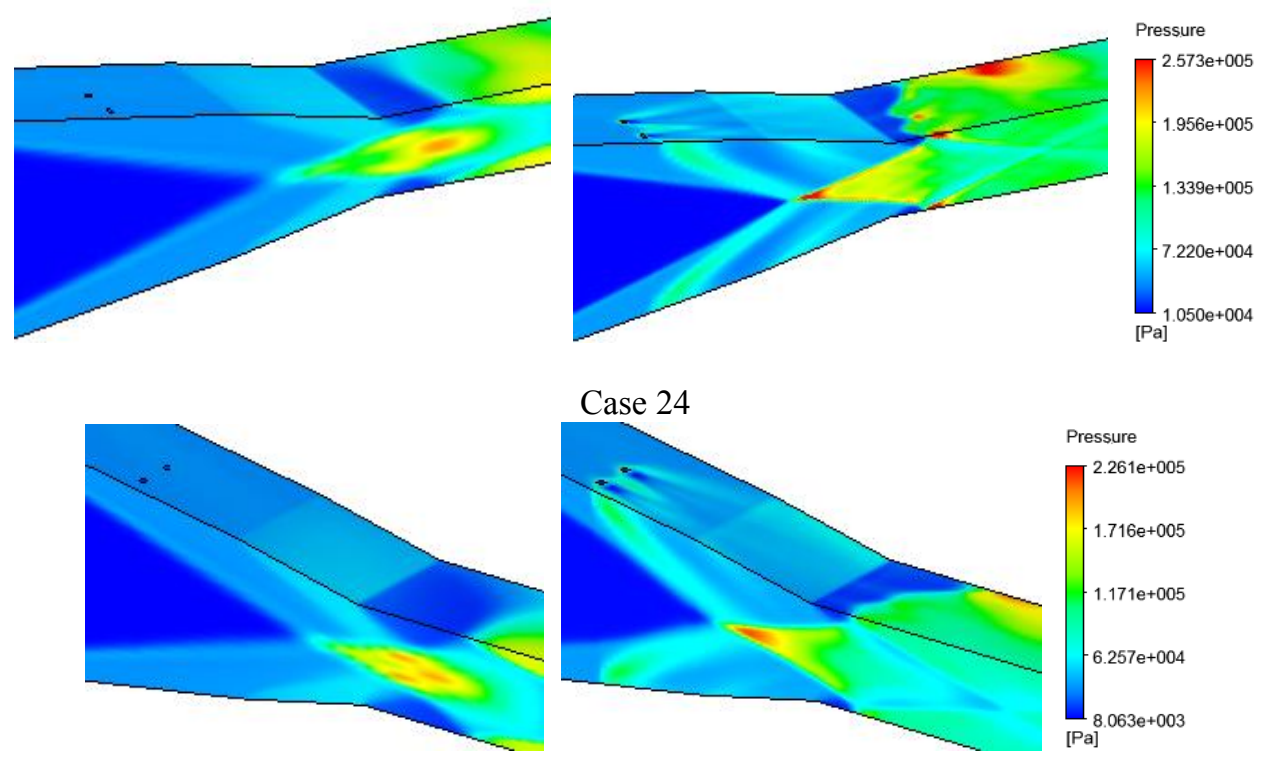

Case 32

Figure 8. Pressure contours for normal flow (left) and frozen flow (right).

The scramjet model used in this study has been designed such that ignition occurs at the first diamond flow structure shape shown in red colour in terms of the pressure contour plot in Figure 8. This region with high pressure and temperature is created by the interaction of shock waves formed from the first and the second compression wedges. However, because of higher Mach number of inlet air flows, the hydrogen jet injected into the transverse airflow may still lack of sufficient penetration depth to reach that region.

However, the shock-induced-combustion can still be triggered; most likely due to the fuel and air gas mixture travelling into the half a diamond flow structures near the upper and the lower combustor surfaces. The flow passing through the region adjacent to the combustor walls will experience the effects similar to those described in the "radical farming" process. The desired "radical farming" process has been partially achieved through the flowfield adjacent the combustor walls. In order for this kind of reaction to progress more efficiently, sufficient temperature, pressure and fuel and air mixing is required. This is beyond the scope of present study and could be a subject for future research. 
Figure 9 shows the distribution of hydrogen mass fraction in the y direction. It can be seen that after the hydrogen is injected into the engine. The concentration near the wall surface is higher, and the penetration depth in the combustion chamber is about $1 / 6$ of the total height. With the increase of equivalence ratio, the jet pressure increases, so that the penetration effect of hydrogen increases. When the equivalent ratio is 0.2 , the hydrogen can only penetrate $1 / 8$ of the combustion chamber height, while the equivalent ratio is 0.8 , the penetration thickness is about $1 / 5$. From the above analysis, we can conclude that the penetration depth and mixing effect are better when the equivalent ratio is high.

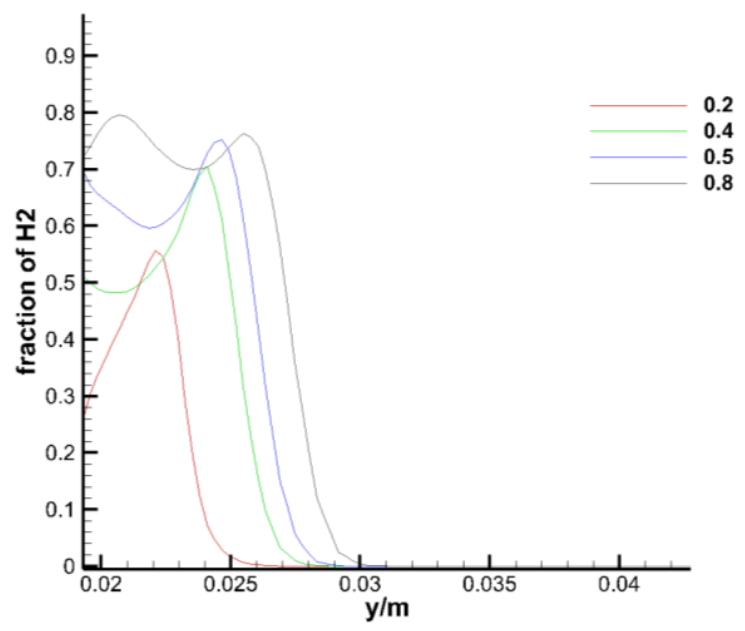

Figure 9. Hydrogen mass fraction in the y direction at different equivalence ratios.

Figure 10 gives the temperature contours of all the three cases, illustrating large temperature raise from the middle zone near the combustor walls. The heat release is also observed in flows with fuel and air mixing and reacting, which increases the temperature and further stronger shock reflection also increases the pressure within the confines of the combustion chamber. The temperature increase will lead to the decrease of the Mach number, hence the flow features generated from the shock and expansion waves and their interactions will be steepened and thus pushing the reflection locations at the walls moving upstream.
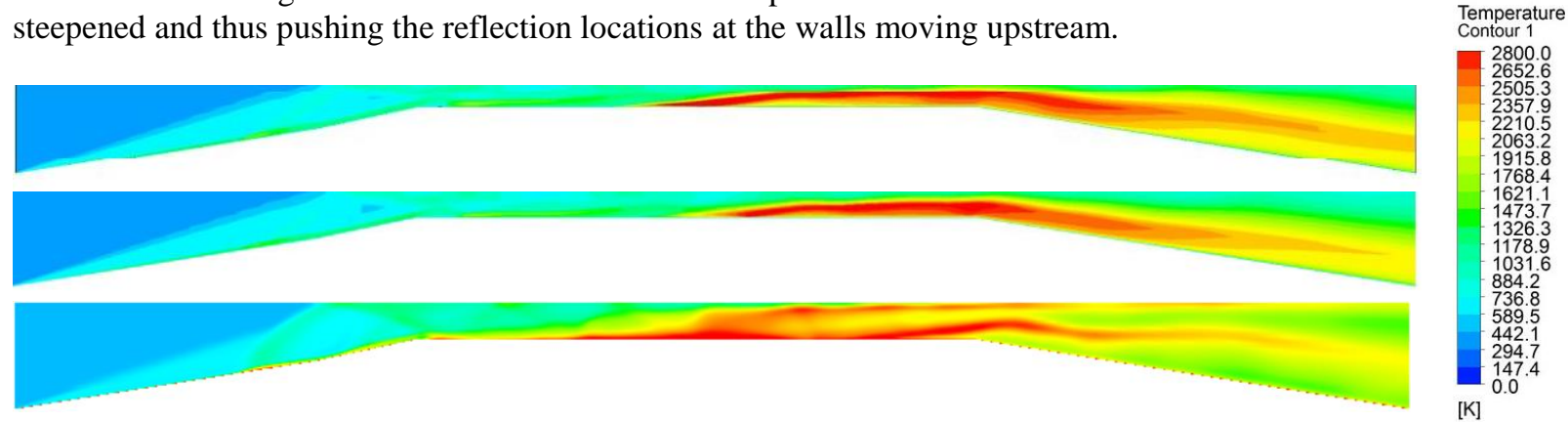

Figure 10. Temperature contours for different combustor height cases.

Figure 11 is the comparison of the pressure distribution between the simulation and the experimental value of the combustion at the equivalence ratio of 0.8 . It can be seen that the simulated results agree well with the experimental results. The combustion occurs earlier in the combustion chamber position compared to the experimental value; leading to the pressure is higher than the test. Because the test rig was not arranged the pressure sensor in the fuel injectors, so the experimental results have not been observed pressure rise. The shock wave structures between the cold flow and combustion are different greatly. At the inlet of the combustion chamber, the first compression wave of with and without combustion is similar. But before the middle of the combustion chamber, due to the effect of the chemical reaction, the compression waves made the pressure and the temperature increase higher than that of the cold flow without reaction. It can be seen from the pressure distribution of the test results, the highest pressure appears in the rear of the combustion chamber, the gas with high temperature and high pressure in the combustion chamber wall reflects. After the two expansion wave, the pressure is decreased obviously. Compared with the 
simulated results, the difference of the wall pressure distribution is mainly reflected the different position of combustion, which results in the influence of the combustion area and pressure distribution.

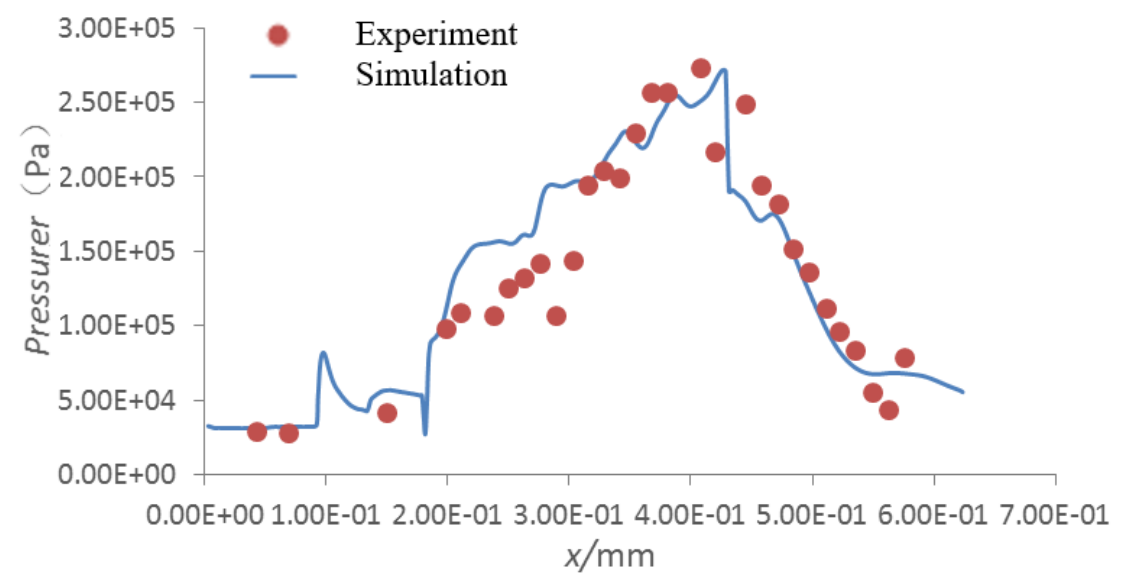

Figure 11. The lower wall centerline pressure distributions for Case 32.

The temperature contours varies with the equivalence ratio from 0.2 to 0.8 for case $32 \mathrm{~mm}$. It can be seen that the high temperature firstly raised in the front of the zone near the combustor walls which is different from the $24 \mathrm{~mm}$ case. But the second high temperature peak was in the middle zone near the combustor walls. The two high temperature zones combined in the back zone of the combustor. The high temperature zone of the case with the equivalence rate 0.5 is spread more widely than that of the other three cases.

It is difficult to accurately assess the 'net' thrust of a scramjet engine with respect to its designed performance by testing the engine alone without integration with the vehicle. Nevertheless, it is still useful to consider the incremental change of the thrust produced by the scramjet engine as a result of fuel addition in primary design stage. The specific thrust, which is used to evaluate the specific 'net' thrust generation of the different models, based on the free stream conditions and the intake capture area can be defined as:

$$
S_{\mathrm{T}}=\left(V_{\text {out }} M_{\text {out }}-V_{\text {in }} M_{\text {in }}\right) / M_{\text {in }} \quad,
$$

where $V$ is the velocity and $M$ is the mass flow rate of the air, subscripts 'in' and 'out' stand for parameters at the inlet and the outlet planes, respectively. Table 3 has shown the results of $S_{T}$ from CFD predictions. The three models are operated at the same flow condition and the equivalence ratio. The specific thrust of Case 24 is found the biggest and the specific thrust value of Case 32 is the smallest. From Figure 15, it can be seen that the outlet temperature of Case 24 is higher and more uniform than other two cases; the $\mathrm{H}_{2}$ mass fraction of the outlet in Table 3 is another corresponding results that can be used as an indicator. Thus, Case 24 consumes more fuel, generating more thrust. This finding agrees with the experimental results in Reference [7]. Considering this situation, further studies will be focused on Case 24 for increasing specific thrust, described in the next chapter.

Table 2. Thrust corresponding to single fuel injector

\begin{tabular}{|c|c|c|c|}
\hline Case No. & 20 & 24 & 32 \\
\hline equivalence ratio $\varphi$ & 0.4 & 0.396 & 0.4 \\
\hline Mach number of inlet & 6.5 & 6.5 & 6.5 \\
\hline specific thrust $(\mathrm{N} \cdot \mathrm{s} / \mathrm{kg})$ & 251.6 & 290.5 & 197.2 \\
\hline $\mathrm{H}_{2}$ mass fraction of outlet & $1.50 \mathrm{e}-4$ & $1.24 \mathrm{e}-5$ & $3.31 \mathrm{e}-4$ \\
\hline
\end{tabular}

\section{Conclusions}

Three-dimensional RANS calculations of non-reactive and reactive flows have been performed using a scramjet model with three different throat heights incorporated with hydrogen fuel injection into the inlet main air stream. The CFD-predicted results are compared with measured wall pressure distributions by experiments with good agreements achieved for both 'fuel off' and 'fuel on' scenarios. It can be concluded, based on the results and discussion that: 
1) For 'fuel off' simulation cases, the predicted wall pressure distributions are in very good agreement with the experimental data and the simulation result is found insensitive to turbulence model tested;

2) The simulation results of combustion flow have shown strong dependence on turbulence model and combustion model choice. Based on this study, a combination of SST turbulence model and EDM combustion model is found the best choice, and the simulation results in terms of wall pressure have shown overall good agreement with experimental data with only a slightly deviation;

3) The effect of fuel injection angle could affect the penetration depth and thus the specific thrust of the scramjet engine. Based on eight injection angles tested, it is found that the scramjet can achieve the best combustion performance when the injection angle is oriented perpendicular to the ramp surface.

\section{Acknowledgments}

This work is supported by the National Natural Science Foundation of China (Grant No. 51406171).

\section{References}

${ }^{1}$ Curran, E. T., "Scramjet Engines: The First Forty Years," Journal of Propulsion and Power, 17 (6), 2001, pp. $1138-1148$.

${ }^{2}$ Rubins, P. M., and Bauer, R. C., "Review of Shock-Induced Supersonic Combustion Research and Hypersonic Applications," Journal of Propulsion and Power, 10 (5), 1994, pp. 593-601.

${ }^{3}$ Billig, F. S., "Research on Supersonic Combustion," Journal of Propulsion and Power, 9(4), 1993, pp. $499-514$.

${ }^{4}$ Curran, E. T., Heiser, W. H., and Pratt, D. T., "Fluid Phenomena in Scramjet Combustion Systems," Annual Review of Fluid Mechanics, 28, 1996, pp. 323-360.

${ }^{5}$ Gardner, A. D., Paull, A., and McIntyre, T. J., “Upstream Porthole Injection in a 2D Scramjet Model," Shock Waves, 11 (5), 2002, pp. 369-375.

${ }^{6}$ Mudford, N. R., Mulreany, P. J., McGuire, J. R., Odam, J., Boyce, R. R., and Paull, A., "CFD Calculations for IntakeInjection Shock-Induced-Combustion Scramjet Flight Experiments," The $12^{\text {th }}$ AIAA International Space Planes and Hypersonic Systems and Technologies, AIAA Paper 2003-7034, Dec. 2003.

${ }^{7}$ Odam, J., "Scramjet Experiments Using Radical Farming," Ph.D. Dissertation, Mechanical Engineering Dept., Univ. of Queensland, Brisbane, Australia, 2004.

${ }^{8}$ Odam, J. and Paull, A., "Radical Farming in Scramjets," New Res. in Num. and Exp. Fluid Mech., VI, NNFM 96, 2007, pp. 276-283.

${ }^{9}$ Brindle, A., Boyce, R. R., and Neely, A. J., "CFD Analysis of an Ethylene-Fueled Intake-Injection Shock-InducedCombustion Scramjet Configuration," AIAA/CIRA 13th International Space Planes and Hypersonic Systems and Technologies, AIAA Paper 2005-3239.

${ }^{10}$ Singh, D.J. and Jachimowski, C.J., "Quasi global Reaction Model for Ethylene Combustion,” AIAA Journal, 32(1), 1994, pp. 213-216.

${ }^{11}$ Star, J. B., Edwards, J. R., Smart, M. K., and Baurle, R. A., "Numerical Simulation of Scramjet Combustion in a Shock Tunnel," The 43 ${ }^{\text {rd }}$ Aerospace Science Meeting and Exhibit, AIAA Paper 2005-0428, 2005.

${ }^{12}$ Jones, J.R., "Numerical Analysis of Shock-Induced Combustion for Scramjet Application," Proceedings of the Australian Combustion Symposium, Dec., 2007.

${ }^{13}$ Chan, J., Sislian, J. P., and Alexander, D., "Numerically Simulated Comparative Performance of a Scramjet and Shcramjet at Mach 11," The 48 ${ }^{\text {th }}$ AIAA Aerospace Sciences Meeting Including the New Horizons Forum and Aerospace Exposition, AIAA Paper 2010-1128.

${ }^{14}$ Buttsworth, D. R. and Jacobs, P. A., "Premature Ignition in Scramjets with Intake Injection: A Preliminary Laminar Mixing Layer Simulation," Proceedings of the Australian Combustion Symposium, Dec., 2009.

${ }^{15}$ Turner, J. C. and Smart, M. K., "Application of Inlet Injection to a Three-Dimensional Scramjet at Mach 8," AIAA Journal, 48 (4), 2010, pp. 829-838.

${ }^{16} \mathrm{http} / / /$ www.ansys.com/products/fluid-dynamics/cfx/

${ }^{17}$ Barth, T. J., and Jespersen, D. C, "The Design and Application of Upwind Schemes on Unstructured Meshes," AIAA Paper 89-0366.

${ }^{18}$ Thivet, F., Knight, D. D., Zheltovodov, A. A., and Maksimov, A. I., “Analysis of Observed and Computed Crossing-ShockWave/Turbulent-Boundary-Layer Interactions," Aerospace Science and Technology, 6 (1), 2002, pp. 3-17.

${ }^{19}$ Xing F., Yao Y., Zhang S., "Numerical Simulation of Shock-Induced-Combustion in Three-Dimensional HyShot Scramjet Model," 50th AIAA Aerospace Sciences Meeting, 2012, AIAA 2012-0945-534.

${ }^{20}$ Menter, F. R., "Two-equation eddy-viscosity turbulence models for engineering applications," AIAA Journal, 32 (8), 1994, pp. $1598-1605$.

${ }^{21}$ Bardina, J. E., Huang, P. G., and Coakley, T. J., “Turbulence Modeling Validation,” AIAA Paper 97-2121.

${ }^{22} \mathrm{Li}$ Q, Yang H, Wang Y., and Wang, P., "Accuracy improvement of the modified EDM model for non-premixed turbulent combustion in gas turbine," Case Studies in Thermal Engineering, 2015, 16: 69-76.

${ }^{23}$ Wilcox D., "Turbulent Modeling for CFD," 3rd edition DCW Industries, 2006. 
${ }^{24}$ Star J., Edwards J., Smart M., Baurle R., “Numerical Simulation of Scramjet Combustion in a Shock Tunnel,” AIAA Paper 2005-0428.

${ }^{25}$ Wang P., Chen M., Xing F., Li Q., "CFD numerical simulation of Hyshot scramjet," Journal of Aerospace Power, 2014,29 (5): 1020-1028. 